\title{
Over View of Thyme Value Chain in Ethiopia: The Case of Dinsho and Tarmaber Areas
}

\author{
Tamirat Girma \\ Kulumsa Agricultural Research Center, P. O. Box 489, Asela, Ethiopia \\ Rehima Musema \\ Ethiopian Institutes of Agricultural Research, P. O. Box 2003, Addis Ababa, Ethiopia
}

\begin{abstract}
:
This paper aimed to explain the value chain of thyme herb in Ethiopia. Potential thyme collection areas Tarmaber and Dinsho were taken for the study. The study employed qualitative data collection method focus group discussion, personal observation and key informant interview. Thyme herb is collected from wild; particularly from bushy or forest areas. The collection took place by local dwellers. The major production and marketing constraints in thyme herb value chain were over grazing, destructive harvesting, limited knowledge of harvesting and processing; and small and volatile supply of the herb. The supply was small and volatile which hindered the herb not to secure sustainable domestic and foreign consumers thus brought difficulty in product branding. Although thyme herb demanded highly in the market the supply was yet dependent on wild thyme collection. Therefore domestication of the plant to garden crop and conservation of the plant genetic resource should be given an emphasis to get benefited from the plant and to rehabilitate the natural wild thyme diversity.
\end{abstract}

Keywords: Spice, Thyme Herb, Tosign

DOI: $10.7176 / J N S R / 12-13-02$

Publication date:July $31^{\text {st }} 2021$

\section{Introduction}

Thyme is a flowering plant in the mint family Lamiaceae. The genus thymus has about 300 species (Copsey and Lerner, 2002). It is commercially produced in a number of countries for both essential oil and dried leaf. The main producing countries are Morocco, Poland, Albania, Turkey, Spain, Portugal, France, Germany and Italy (Prakash, 1990 and Trumpy, 2012). The biggest production in Africa is in the Atlas Mountain South of Morocco. 3,000 to 3,500 metric tons were harvested from the wild every year of which $77 \%$ is traded (Trumpy, 2012). USA, Germany, Denmark, France and Scandinavian countries are major importers.

Thyme is known by its local name tosign in Ethiopia. Two species of thyme, (Thymus Schimperi and Thymus serrulatus), are indigenous and used for medicinal and spice purposes in the country (Destaw and Yalemtsehay, 2015). The crop is consumed as tea alone and used as spice in major meal components. Ethiopian women are very much conscious that this crop is an important crop to flavor their food. A woman that can make spicy food that has good flavor and test is known as balemoya (expertise of traditional food) thus they want to show their skill by making spicy food that could attract the consumers. Thyme as spice is used to flavor foods like shiro, besso, and milk products like ergo (yoghurt), butter and cheese. Shiro is powder prepared from legume crops like bean and peas use to prepare Ethiopian stew (wot) whereas besso is a powder prepared from roasted barley and consumed softening by water (possibly by milk, batter). Thyme additionally used as honey bee forage, animal forage and fumigating household utensils such as buckets for milking and dough preparation (Destaw and Yalemtsehay, 2015).

As traditional medicine thyme is known remedy for coughs, diarrhea, digestive disorders and respiratory diseases. Kassie and Chandravanshi (2016) also reported the same in their study. Thyme tea is widely taken form of thyme herb as medicine and additionally it has been taken with different drinks like local alcohol (areke), tea and coffee in different parts of the country.

Thyme in modern application, thyme has been thought of to be antiseptic, antimicrobial, medication, astringent, anthelmintic, medicinal drug, carminative, disinfectant, medicinal drug and tonic. Thyme is incredibly useful in cases of assorted intestinal infections and infestations, like hookworms, gram-positive and gram-negative bacterium, fungi and yeasts. Its active constituent, thymol, is active against enterobacteria and cocci bacteria (Prasanth et al. 2014).

Essential oil of thyme has a wide range of applications in the manufacturing of liqueurs, perfumes, pharmaceutical products and sanitary products. The essential oil thyme is used to preserve processed meat and butter, and in making chewing gum, ice cream, candy, and the liqueur Benedictine. It is used for skin problems such as oily skin, sciatica, acne, dermatitis, eczema and insect bites (Basch et al, 2004).

Despite its importance, research works that focused on thyme plant is limited in the country. The available research efforts were focused on identification of chemical composition of the crop. Even if thyme has been widely traded in all local, districts, zonal and central markets in Ethiopia, there was scanty of information on the 
production, processing and marketing of the crop. Value chains facilitate a clear understanding of the sequence of thyme production, processing and trading activities and the key actors and their relationships. Therefore the objectives of this study were:

○ Identifying the value chain actors involved in production, processing and utilization thyme and their role in the value chain.

- Assessing production and marketing constraints of thyme technologies.

○ Suggest strategies for the promotion of thyme technologies

\section{Methodology \\ Description of the study areas}

The study focused on two thyme collection areas (Dinsho and Tarmaber). Both Dinsho and Tarmaber were among the main collection areas for wild thyme herb in the country. Dinsho is located in the Bale Zone of the Oromia Region in the heart of the Bale Mountains. It is located $400 \mathrm{~km}$ South-East of Addis Ababa, the country's capital. Agro climatologically the district covers, 95\% highland (Dega) and 5\% semi-arid (Woinadega). The altitude of the district varies from 2000 to 3600 meters above sea level (Wikipedia, 2011). Tarmaber is one of the kebelas in Mojana Wadera District in the Amhara Region of Ethiopia. It is located $190 \mathrm{~km}$ away from Addis Abeba. Agro climatologically 17\% of the land is lowland, $28 \%$ semi-arid (Woinadega) and $54.7 \%$ is highland (Dega). Its altitude is ranging from 1500 to 3100 meter above sea level. (Destaw and Yalemtsehay, 2015)

\section{Method of data collection and analysis}

The study employed qualitative data collection methods including rapid appraisal, key informant interview, focus group discussion and personal observation. The study used information from two FGD (one per collection area), 8 key informants and 15 wild collectors and traders. Wild thyme collectors and different value chain marketing actors in potential thyme markets like Bale, Dinsho, shahsemene and Addis Abeba from Oromia region and Tarmaber, Debre Brehan and Debre Sina from Ahmara region were covered by the study. The current assessment did not intensively address quantitative issues due to irregular nature of the collection and engaged traders.

\section{Results and Discussion \\ Thyme Production}

Statistics on the production of aromatic and spice plants like thyme is very difficult to come by in Ethiopia as the commodities were not part of the national agricultural crop survey and thus the traded amount were not evidently known. Thyme has been collected from wild in many parts of Ethiopian highlands. In Dinsho, the plant was collected from natural forest around bale national park. This aromatic and spice plant is not considered for farm level production in the area. It grows naturally on mountains between other bushy plants surviving from uncontrolled animals grazing and over harvesting. Since the plant grows surrounding Bale national park both wild and domestic animals have an access to graze it.

Around Tarmaber and Debresina thyme grows mainly in manmade forest (between eucalyptus trees) and on plateaus area used for cattle grazing.

Domestication of this crop as garden crop with research based agronomic management could create greater access to the produce, and thereby reduces vulnerability of the crop to extinction in the longer term. Marshall (2011) indicated that in the presence of limited cultivation options, popularly traded species have become overexploited.

\section{Herbal thyme trade in Ethiopia}

Ethiopian thyme is traded both domestically and abroad. Approximately more than $50 \%$ of thyme is consumed domestically. Ethiopia also exports thyme even if the supply was irregular and difficult to get the current exported amount. Thyme export had been declining by $85 \%$ annually even if the price had shown an increasing trend by $27 \%$ (Fig. 1 ). The reason for this may be the reduction in the supply as also indicated by $63 \%$ of thyme collectors during interview. 


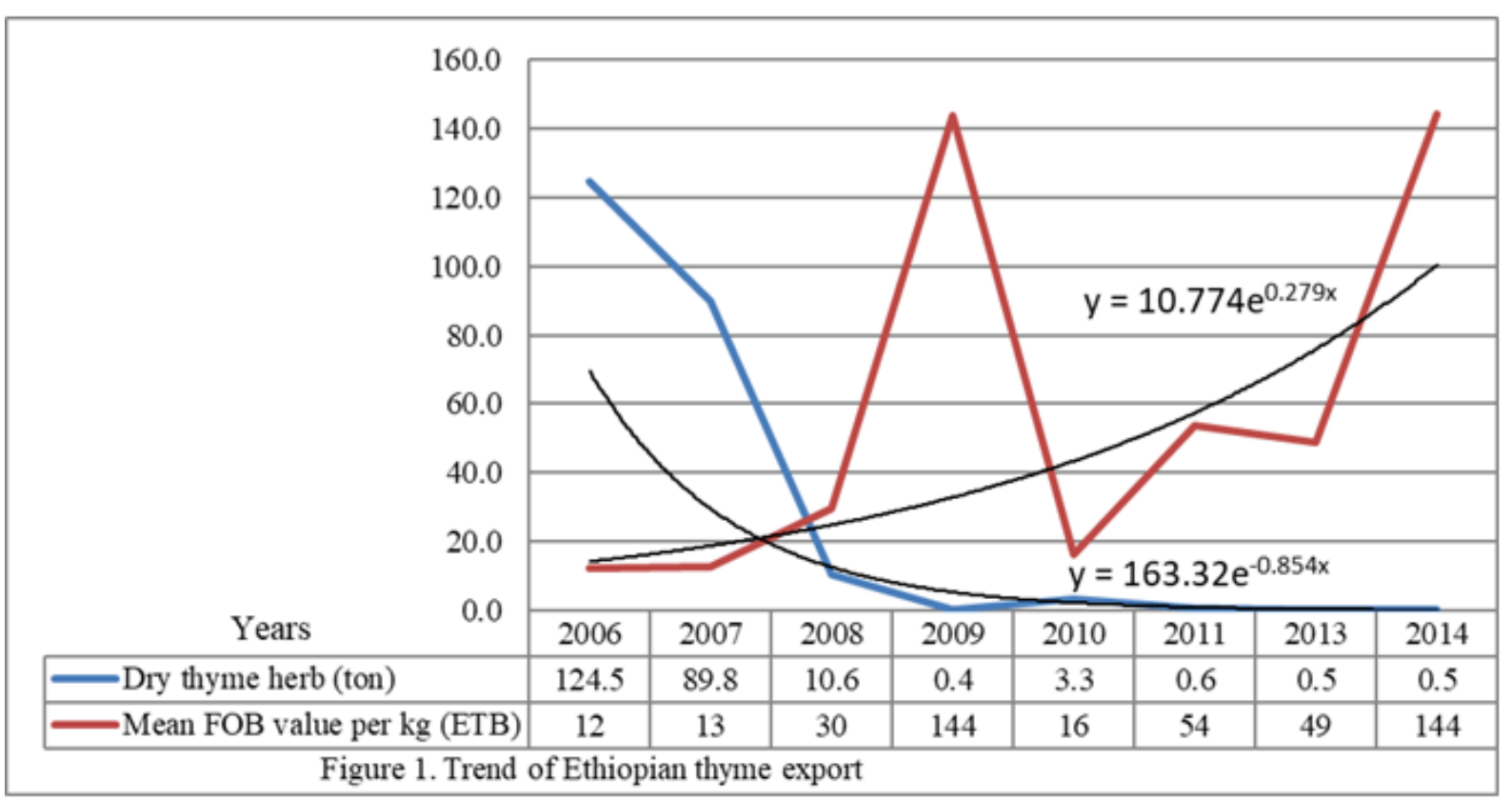

Source: Ethiopian horticulture agency and custom and revenue authority

The destination of majority (53\%) of Ethiopian thyme was United Arab Emirates and Saudi Arabia followed by United States of America (43\%), Djibouti (3\%), Norway (1\%), Canada (0.3\%) and Finland (0.1\%).

There are three main outlets by which the wild thyme collectors sell the herb. Wild thyme collectors sell their herb for collectors, retailers and consumers. Generally there are about 8 market channels comprising different marketing actors through which thyme herb reaches consumers (Fig.2).

I. Wild thyme collectors $\rightarrow$ Collector traders $\rightarrow$ Wholesalers $\rightarrow$ Retailers $\rightarrow$ processors $\rightarrow$ Consumers

II. Wild thyme collectors $\rightarrow$ Collector traders $\rightarrow$ Wholesalers $\rightarrow$ W Retailers $\rightarrow$ Consumers

III. Wild thyme collectors $\rightarrow$ Collector traders $\rightarrow$ Retailers $\rightarrow$ processors $\rightarrow$ Consumers

IV. Wild thyme collectors $\rightarrow$ Collector traders $\rightarrow$ Retailers $\rightarrow$ Consumers

V. Wild thyme collectors $\rightarrow$ Collector $\rightarrow$ Wholesalers $\rightarrow$ Foreign importers

VI. Wild thyme collectors $\rightarrow$ Retailers $\rightarrow$ processors $\rightarrow$ Consumers

VII. Wild thyme collectors $\rightarrow$ Retailers $\rightarrow$ Consumers

VIII. Wild thyme collectors $\rightarrow$ Consumers

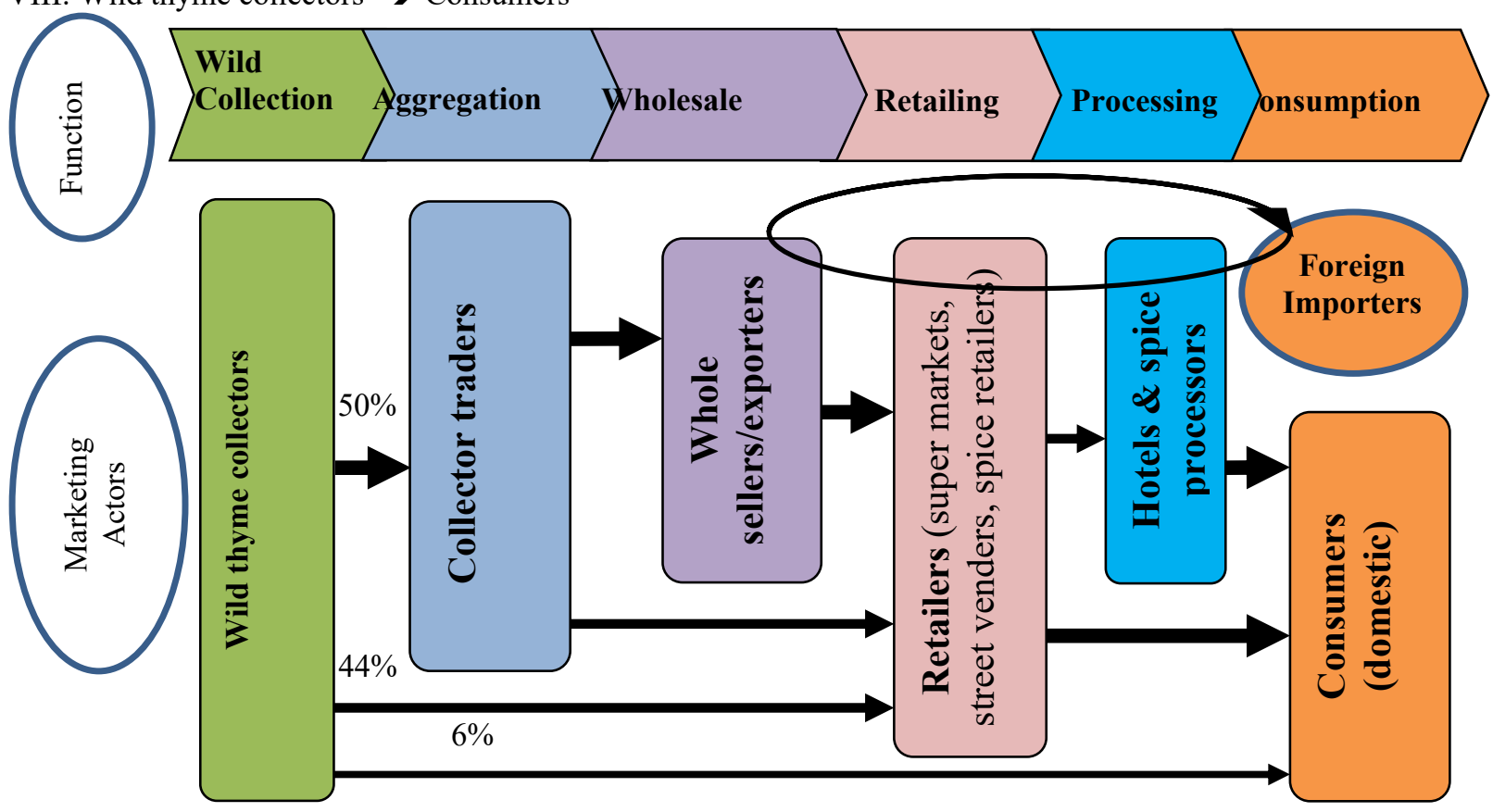

Figure 2. Map of herbal thyme value chain 


\section{Wild thyme collection (wild thyme collectors)}

Collection of thyme is usually conducted by rural communities that are located in the neighborhood of forest areas in Dinsho; whereas both rural and urban dwellers participate in thyme collection in Tarmaber.

Months of September, October and November are the best period of thyme collection. Almost half of the dried quantity is sold for collector traders and $44 \%$ for retailers and $6 \%$ for consumers.

Wild thyme collectors uproot or cut the plant and gather it in sack to bring the produce to their home. Although the collection of thyme does not require very sophisticated knowledge and skills, collectors usually apply improper harvesting practices and wrong collection methods damaging the nature and genetic resource of the plant. They uproot the plant unintentionally to get higher biomass in a short period of time. This seizure leads to the extinction of the plant through time and the collectors do not notice or do not care of the problem much, because their activities are not monitored and they are not trained for that. Sustainability, legality of access and the method of collection for indigenous plants need to be ascertained.

Thyme collection is undertaken by female and children in both Dinsho and Tarmaber. The collection is mostly done as additional work in Dinsho by superimposing with fire wood collection and cow shepherding whereas it is main and independent activity in Tarmaber.

Collector traders: These traders gather dried thyme herb from wild collectors and distribute to wholesalers and retailers in nearby or central market (Addis Abeba). They buy dry thyme from wild collector and sell in either local markets or transport it to potential markets like Addis Abeba, Hawassa, Mekele, Dessie, Shashemene, Adama, etc.

Wholesalers: Wholesalers are purchasers of thyme her for domestic or international markets. These are central market traders that purchase spices. They conduct operations like storing, cleaning, classifying and packaging. The export of thyme is not sustainable activity due to insufficient supply and quality related issues.

Retailers: Retailers buy thyme from wild collectors, collector traders and wholesalers. These agents conduct operations like sieving and classifying. Retailers that trade thyme on the roadside conduct packaging to avail the product as consumers need.

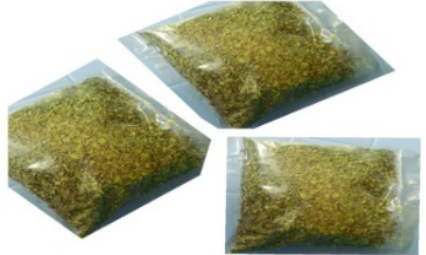

Consumers: Thyme is consumed alone as a tea and as spice in other foods like shiro and beso. Consumers of thyme can be classified into domestic and foreign consumers. Thyme is one of the major spices used almost by all of Ethiopians with different foods.

Processors: Processing of thyme was done in different ways. Spices processors grind and mix different types of spices whereas hotels process thyme to make ready for consumption as tea and condiment. Some traders pack dry thyme herb in plastic bag and make ready for easy handling and consumption.

\section{Processing in thyme value chain}

\section{Indigenous Knowledge of Herbal Thyme Preparation}

After collection of thyme the primary processing including drying and leaf separation is done by wild thyme collectors. Drying is the immediate activity after the collection of thyme because the quality of thyme highly affected by drying. If there is a delay before drying the color and the aroma of the thyme will be changed to disfavored color in the market. Wild thyme collector processors practiced two types of drying. The first is sun drying. This method of drying is practiced during sunny days. The other is smoke drying method. In this method, thyme is hung over the roof of their house for two to three days. This method is used during the rainy days (season). After drying, leaf separation is the next processing activity. The leaf of thyme is separated using stick beating after two to three days of drying. Then the produce is sieved to remove foreign materials and made ready for market. Finally the herb is packed in different amount according to the buyers' category. 


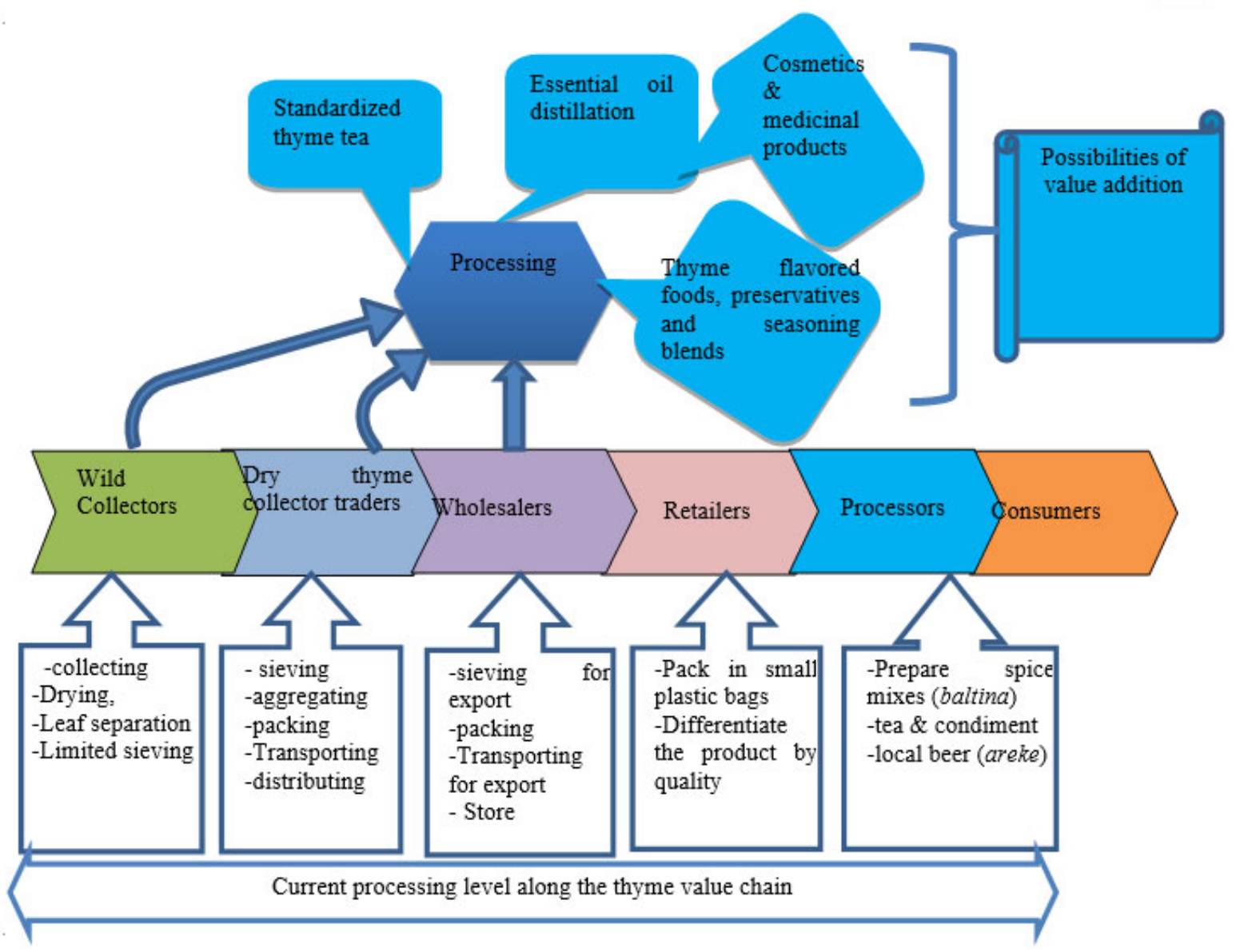

Figure 3. Processing and possibilities of value addition

\section{Opportunities and Constraints in Thyme Value Chain}

Table1. Opportunities, Constraints and Interventions required

\section{Opportunities}

Demand in domestic \& foreign markets like USA European, and Asian markets

Existence of traditional spice processing

Knowledge (opportunity of promoting domestic spice and formulated foods for international consumers (eg. Shiro \& beso)

There is favorable agro ecology (dega \& woina $\operatorname{deg} a)$

Wide range of value addition. It can be used as flavoring, drinks, medicine and cosmetics sstraints

Over and destructive harvesting, over grazing \& expansion of agricultural land (Thyme resource is declining)

There is almost no scientific information in Ethiopia on varieties, productivity, affecting pest and diseases, profitability of the crop \& agronomic managements.

No breeding \& agronomic researches done

Weak post-harvest management. Eg. sun drying(over drying) is not recommended drying method for aromatic herbs because it affects essential oil content that finally decreases the quality

Weak horizontal and vertical integration among value chain actors.

No association /cooperative/ that organizes the production \& marketing and the information flow

\section{Interventions required}

Environmental protection works has to be strengthened.

Awareness has to be created for thyme collectors and controlling mechanism on overharvesting has to be installed.

Research has to be strengthened to address technological gaps

Introduction of appropriate postharvest technology and Utilization of international quality standards

(American Cleanliness Specifications ASTA, HACCP, GAP, ISO 9000, ISO 22000, ISO 6754:1996)

Organizing strong spice and aromatic plant producing and marketing cooperative could be seen as a solution 


\section{Opportunities $\quad$ straints}

No production and marketing data which makes the trade difficult for agents and investors (no prior planning).

Difficult to know the supply condition that creates price volatility

Limited value addition (essential oil and formulated products, standardized tea, etc)

The supply is small and volatile to create sustainable foreign customer and product branding. Thyme was not cultivated in garden and the production cannot be easily regulated.
Interventions required

Production and marketing data like areas of production, production potential and amount supplied for market should be collected for this herb by governmental office like Central statistical agency so that it become easy for value chain actors to plan

Government have to promote, enhance and support processors in this sector to change the available potential into opportunity

Domestication of the plant is necessary principally supported by research based technologies

\section{Conclusions and suggestions}

In Ethiopia, thyme is collected from wild. The collection took place by local dwellers for additional income generation and own use. The major constraints in thyme value chain were over and destructive harvesting, lack of technical know-how on production; harvesting and processing and lack of structured marketing. Overexploitation of the plant resource has been resulting in a decline of the thyme herb supply. Bringing thyme into garden production could open an alternative income generation for producers and the country. Therefore domestication of the plant to garden crop and conservation of this plant has to be given an emphasis to get benefited from the crop sustainably and to rehabilitate the natural wild thyme diversity. Researches have to work to address technological gaps related to variety, agronomic managements, post-harvest handling and processing. Commercialization level of collected thyme particularly as export crop is very low due to small volumes, limited quality and lack of sustainable supply. Therefore it is important to improve commercialization of thyme through improvement of destination market requirements.

\section{Reference}

Basch E, Ulbricht C, Hammerness P, Bevins A, Sollars D. (2004). Thyme (Thymus vulgaris L.), Journal of Herbal Pharmacotherapy, 4(1): 49-67.

Copsey K. and Lerner B. (2002). Growing Herbs Department of Horticulture Purdue University Cooperative Extension Service General Horticulture • HO-28-W

Destaw D. and Yalemtsehay M. (2015). Thymus species in Ethiopia: Distribution, medicinal value, economic benefit, current status and threatening factors. Ethiop. J. Sci. \& Technol. 8(2): 81-92

Kassie Nigus and Bhagwan Singh Chandravanshi. (2016). Levels of Fluoride in Widely Used Traditional Ethiopian Spices. Research Report. Fluoride 49(2):165-177

Marshall E. (2011). Health and wealth from Medicinal plants. FAO Diversification booklet number 17. Rome, 2011

Prakash, V. (1990) Leafy spices. CRC Press, Inc., Boca Raton, Florida, USA.

Prasanth Reddy, Ravi Vital Kandisa, Varsha PV and Satyam S. (2014). Review on Thymus vulgaris Traditional Uses and Pharmacological Properties http://dx.doi.org/10.4172/2167-0412.1000164

Trumpy S. (2012). Herbs Market Report, $11^{\text {th }}$ World Spice Congress, 2012

Wikipedia. (2018). https://en.wikipedia.org/wiki/Dinsho_(woreda) 